\title{
DISGENESIA DO CORPO CALOSO E MÁS-FORMAC̣ÕES ASSOCIADAS: ACHADOS DE TOMOGRAFIA COMPUTADORIZADA E RESSONÂNCIA MAGNÉTICA*
}

\author{
Cristiano Montandon ${ }^{1}$, Flávia Aparecida de Sousa Ribeiro ${ }^{2}$, Leonardo Valadares Barbosa Lobo ${ }^{2}$, \\ Marcelo Eustáquio Montandon Júnior ${ }^{1}$, Kim-Ir-Sen Santos Teixeira ${ }^{3}$
}

Resumo 0 termo disgenesia do corpo caloso refere-se a uma má-formação deste com origem na embriogênese do telencéfalo. $O$ relato analisa os achados de tomografia computadorizada e ressonância magnética em 11 pacientes com disgenesia calosa e em um caso de corpo caloso normal com lipoma associado. Esta pode ser distinguida em três grupos: agenesia total (três casos), agenesia parcial (seis casos) e hipoplasia (dois casos). Anomalias associadas foram observadas em nove casos, incluindo má-formação de Chiari tipo II (um caso), esquizencefalia (um caso), cisto inter-hemisférico (dois casos), heterotopia nodular (um caso), cisto de Dandy-Walker (um caso) e lipoma do corpo caloso (quatro casos). Este artigo demonstra um espectro destes distúrbios, auxiliando na sua interpretação diagnóstica.

Unitermos: Disgenesia do corpo caloso; Má-formação cerebral; Anomalias do desenvolvimento; Lipoma do corpo caloso.

Abstract Dysgenesis of the corpus callosum and associated malformations: computed tomography and magnetic resonance imaging findings.

Callosal dysgenesis is a malformation of the corpus callosum with origins in the embryogenesis of the telencephalon. We reviewed the computed tomography and magnetic resonance imaging findings of 11 patients with callosal dysgenesis and one patient with normal corpus callosum associated with a lipoma. The patients were divided into three distinct groups: total agenesis (three patients), partial agenesis (six patients) and hypoplasia (two patients). Associated abnormalities were observed in nine patients, including Chiari II malformation (one patient), schizencephaly (one patient), interhemispheric cyst (two patients), Dandy-Walker cyst (one patient), nodular heterotopy (one patient) and lipoma of the corpus callosum (four patients). This paper presents a review that may contribute to the diagnosis of these disorders.

Key words: Dysgenesis of the corpus callosum; Brain malformation; Developmental anomalies; Lipoma of the corpus callosum.

\section{INTRODUÇÃO}

A expressão disgenesia do corpo caloso aplica-se a variáveis graus de sua máformação, desde a ausência total até mínima deficiência no seu desenvolvimento ${ }^{(\mathbf{1})}$. Assim, existem várias desordens relacionadas à formação do corpo caloso, entre elas as agenesias total e parcial, a hipoplasia e os lipomas da fissura inter-hemisférica ${ }^{(2-4)}$.

*Trabalho realizado na Clínica da Imagem e no Departamento de Diagnóstico por Imagem e Anatomia Patológica do Hospital das Clínicas da Universidade Federal de Goiás (HC-UFG), Goiânia, GO.

1. Médicos Radiologistas, Membros Titulares do Colégio Brasileiro de Radiologia e Diagnóstico por Imagem (CBR).

2. Médicos Estagiários em Radiologia do Departamento de Diagnóstico por Imagem e Anatomia Patológica do HC-UFG.

3. Médico Radiologista, Membro Titular do CBR, Professor Ad junto Doutor do Departamento de Diagnóstico por Imagem e Anatomia Patológica do HC-UFG.

Endereço para correspondência: Dr. Cristiano Montandon. Avenida Ismerino S. Carvalho, 775, Setor Aeroporto. Goiânia, GO, 74075-040. E-mail: cabeca2@terra.com.br

Recebido para publicação em 21/2/2003. Aceito, após revisão, em 11/3/2003.
As anormalidades do corpo caloso estão geralmente associadas a outras anomalias do telencéfalo, haja vista serem formados na mesma época de desenvolvimento, sugerindo serem estas alterações relacionadas com a mesma embriogênese ${ }^{(\mathbf{3 , 4})}$.

$\mathrm{O}$ advento da tomografia computadorizada (TC) e, principalmente, da ressonância magnética (RM) tornou o diagnóstico das afecções do corpo caloso mais fácil e mais acurado. A TC é de longe a mais utilizada, porém tem como principal desvantagem não mostrar uma anatomia ideal do corpo caloso, sendo necessários cortes finos contíguos para reformatações no plano sagital, com aumento significativo de radiação ionizante. Já a RM, por permitir aquisição de imagens multiplanares e não utilizar radiação ionizante, apresenta uma maior vantagem sobre a TC, porém tem como desvantagens o seu alto custo e inacessibilidade por parte da população ${ }^{(5)}$.
Neste artigo se faz uma revisão dos principais achados e padrões das lesões congênitas do corpo caloso na TC e na RM, as quais constituem métodos não-invasivos para avaliação do encéfalo, auxiliando no diagnóstico e na decisão terapêutica.

\section{MATERIAIS E MÉTODOS}

O estudo foi realizado retrospectivamente, por meio de revisão de casos de disgenesia do corpo caloso e más-formações associados, oriundos do Hospital das Clínicas da Universidade Federal de Goiás (UFG) e da Clínica da Imagem, Goiânia, GO, no período de março de 1998 a setembro de 2002, reunindo um total de 12 casos. Seis pacientes foram submetidos a TC de crânio, em aparelho Somatom AR convencional Siemens, e seis a RM, em aparelho Giroscan T1.0-NT Philips. Entre os pacientes estudados, sete eram do sexo 
feminino e cinco eram do sexo masculino, com idades variando de 10 meses a 57 anos, com média de 17 anos.

\section{RESULTADOS}

A partir da época do insulto e dos eventos que culminam com a disgenesia do corpo caloso, os métodos de imagem podem classificá-la nas seguintes formas: tipo I, ou agenesia total, em que o corpo caloso está completamente ausente; tipo II, agenesia parcial ou hipogenesia, cujo corpo caloso apresenta graus variados de encurtamento causados principalmente por fatores interruptivos primários ou relacionados a obstrução orgânica; e tipo III, ou hipoplasia, em que o corpo caloso é completamente formado, porém apresenta redução em seu tamanho, podendo ser focal ou difusa, e em geral está associada a importantes alterações do córtex ${ }^{(\mathbf{3 , 4})}$.

Foram encontradas as seguintes associações a disgenesias do corpo caloso: complexo de Dandy-Walker, má-formação do tipo Chiari, distúrbios da migração neuronal (esquizencefalia, heterotopia nodular e displasias corticais), defeito da linha mediana (lipomas curvilíneos e túbulonodulares) e encefalomalácia periventricular (Tabela 1).

\section{DISCUSSÃO}

\section{Embriologia e anatomia}

O corpo caloso é formado no sentido anterior para posterior, com exceção do rostro, último a se formar. A agenesia do corpo caloso pode ser total ou parcial; se for parcial, o esplênio e o rostro estarão sempre ausentes (Figura 1). A presença de esplênio normal com algum grau de alteração do joelho ou corpo é indicativo de um processo secundário e não devido a formação primária, caracterizando, assim, a hipoplasia (Figura 2) ${ }^{(6,7)}$.

O corpo caloso adquire a forma adulta por volta da 17ª semana de gestação, quando começa a se espessar com a maturação do córtex cerebral, usualmente de anterior para posterior $^{(\mathbf{1})}$.

O ponto crucial na embriogênese do corpo caloso está no surgimento da placa comissural no aspecto dorsal da lâmina terminal, entre a $10^{\mathrm{a}}$ e a $12^{\mathrm{a}}$ semanas de

Tabela 1 Distribuição dos casos segundo a idade, sexo, métodos de imagem, diagnóstico e associações.

\begin{tabular}{|c|c|c|c|c|c|}
\hline Casos & Idade & Sexo & Método & Diagnóstico & Associações \\
\hline 1 & 10 meses & M & TC & Agenesia parcial do corpo caloso & Chiari tipo I \\
\hline 2 & 1 ano & $\mathrm{F}$ & TC & Agenesia parcial do corpo caloso & $\begin{array}{l}\text { Esquizencefalia } \\
\text { Cisto inter-hemisférico }\end{array}$ \\
\hline 3 & 8 anos & $\mathrm{F}$ & RM & Corpo caloso normal & Lipoma curvilíneo \\
\hline 4 & 9 anos & $\mathrm{F}$ & RM & Agenesia parcial do corpo caloso & - \\
\hline 5 & 9 anos & M & TC & Agenesia parcial do corpo caloso & Lipoma \\
\hline 6 & 11 anos & M & TC & Agenesia total do corpo caloso & Lipoma \\
\hline 7 & 12 anos & $\mathrm{F}$ & TC & Agenesia total do corpo caloso & $\begin{array}{l}\text { Dandy-Walker } \\
\text { Cisto inter-hemisférico }\end{array}$ \\
\hline 8 & 15 anos & $\mathrm{F}$ & RM & Hipoplasia do corpo caloso & Leucomalácia periventricular \\
\hline 9 & 19 anos & M & RM & Hipoplasia do corpo caloso & Heterotopia nodular \\
\hline 10 & 28 anos & $\mathrm{F}$ & $\mathrm{TC}$ & Agenesia parcial do corpo caloso & - \\
\hline 11 & 35 anos & $\mathrm{F}$ & RM & Agenesia parcial do corpo caloso & Lipoma do corpo caloso \\
\hline 12 & 57 anos & M & TC & Agenesia total do corpo caloso & - \\
\hline
\end{tabular}

$M$, masculino; $F$, feminino.

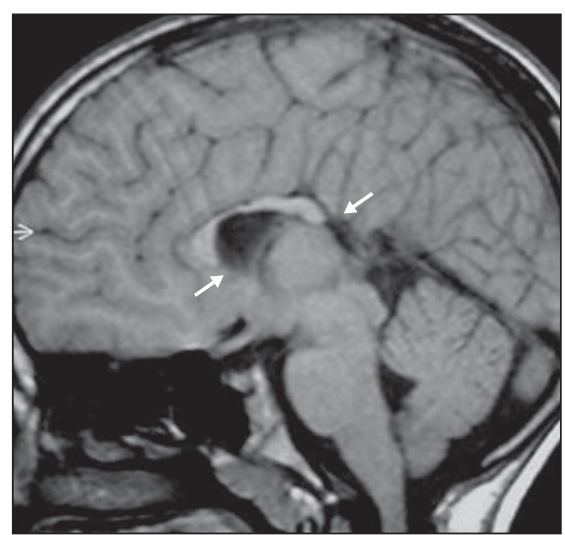

A

Figura 1. Agenesia parcial do corpo caloso (caso 4). A: RM SE T1 sagital - ausência do esplênio e do rostro do corpo caloso (setas) e redução volumétrica do seu joelho e corpo; B: RM SE T1 coronal - afilamento do corpo caloso.

gestação fetal. O papel da placa comissural é atuar como indutora do leito para a decussação das fibras comissurais calosas. Se a placa comissural não ocorre, não há decussação de fibras, o que acarretará em agenesia primária total do corpo caloso. A indução desencadeada pela placa comissural é o primeiro passo, a qual deve ser mantida até o término da decussação. Se nesta época este processo for interrompido em qualquer ponto, resultará numa "hipogenesia interruptiva" ou agenesia parcial do corpo caloso. Estas são causas primárias de disgenesias, sendo de etiologia desconhecida, podendo estar relacionadas a diversos fatores, entre eles: agentes infecciosos, químicos, radiação, hormônios maternos, deficiência nutricional, hipóxia, fatores genéticos e cromossomais ${ }^{(2,4)}$.

Outra forma de hipogenesia é provocada pela obstrução orgânica, tendo como

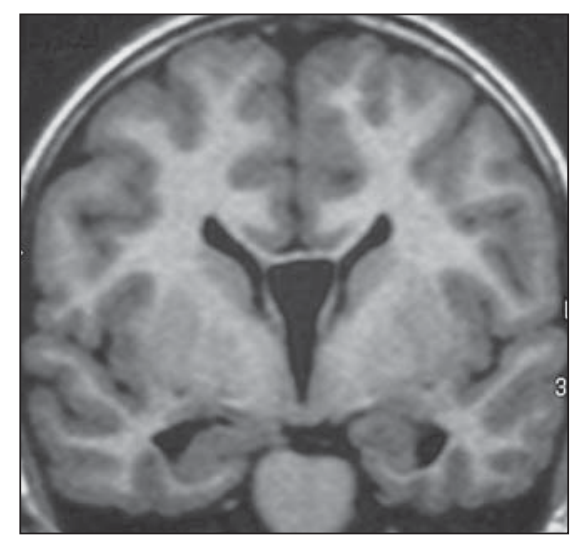

B

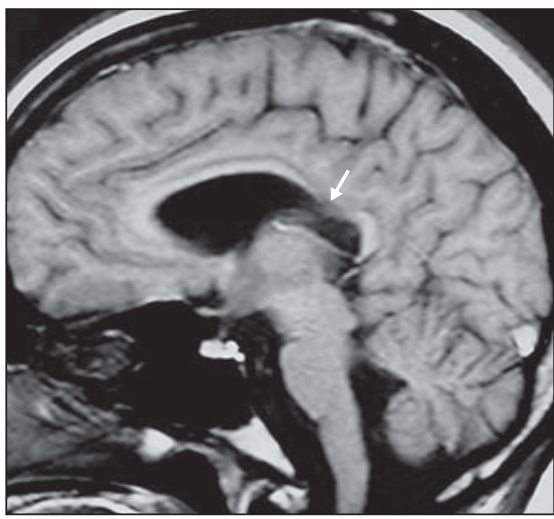

Figura 2. Hipoplasia do corpo caloso (caso 8). RM SE T1 sagital - hipoplasia do corpo do corpo caloso (seta).

principal causa lesões lipomatosas. Este fenômeno está relacionado ao fechamento do tubo neural, entre a $3^{\underline{a}}$ e a $5^{\underline{a}}$ semanas de gestação, e antecede a decussação das fibras do corpo caloso. Sendo assim, 
durante a formação do tubo neural, os restos heterotópicos de gordura podem ser incluídos na profundidade do telencéfalo em desenvolvimento e, portanto, na posição do corpo caloso, resultando numa colisão embrionária. O grau de disgenesia secundária associada a estas inclusões varia de acordo com o tamanho do lipoma e sua localização. Há também a possibilidade de o lipoma coexistir incidentalmente com agenesia primária do corpo caloso e não ser causa direta na geração desta máformação ${ }^{(2,4,6)}$.

Existem várias teorias tentando explicar a origem embriológica dos lipomas do corpo caloso, mas a mais provável é a falha de absorção das meninges primitivas, as quais preenchem as cisternas do cérebro embrionário no primeiro trimestre. A persistência deste tecido meníngeo ocorre em vários graus e há maturação para tecido adiposo. Portanto, o lipoma é considerado uma condição hamartomatosa congênita ${ }^{(7-10)}$.

A hipoplasia do corpo caloso tem sua origem a partir de anormalidades na migração neuronal ou na laminação das camadas corticais, ou seja, na displasia cortical. A etiologia é desconhecida, porém postula-se ser este tipo de disgenesia calosa decorrente de um insulto no córtex cerebral ou na substância branca após o corpo caloso estar completamente formado, por volta da $18^{\underline{a}}$ à $20^{\underline{a}} \operatorname{semanas}^{(\mathbf{4 , 7})}$ (Figura 3 ).

Portanto, para a formação do corpo caloso são necessários dois processos: o desenvolvimento do precursor do corpo

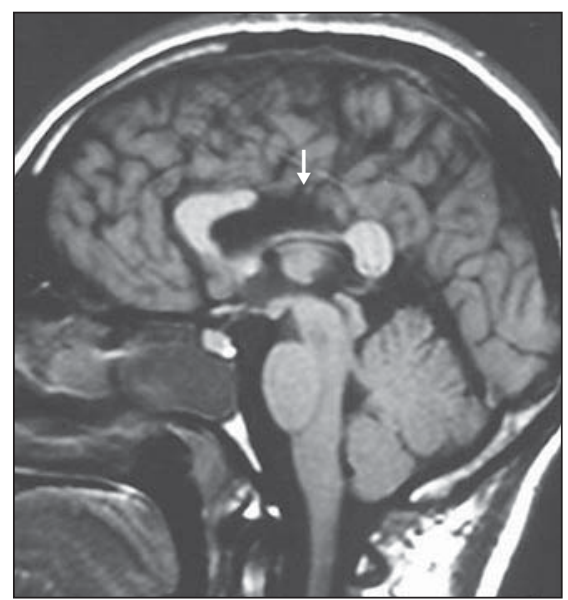

A

Figura 3. Hipoplasia do corpo caloso (caso 9). A: RM SE T1 sagital - ausência do corpo do corpo caloso (seta); B: RM IR T1 coronal - heterotopia nodular periventricular (seta). caloso e a decussação das fibras das vesículas hemisféricas. O defeito na formação do corpo caloso pode resultar de um déficit na indução de seu precursor e na decussação, resultando em uma agenesia total ou parcial, ou do erro no desenvolvimento das fibras de associação, levando à hipoplasia. O grau de disgenesia do corpo caloso e de anormalidades telencefálicas associadas também depende da época do insulto ${ }^{(3,4)}$.

\section{Distribuição e quadro clínico}

A incidência de disgenesia do corpo caloso é desconhecida, sendo a maioria dos casos esporádica. Não há prevalência entre os sexos. A maior parte dos pacientes é assintomática. Alguns podem apresentar síndrome de desconexão cerebral, em que o aprendizado e a memória não são partilhados entre os dois hemisférios. Convulsões e retarde do desenvolvimento neuropsicomotor provavelmente são secundários a outras desordens associadas, como as de migração neuronal e não propriamente à anomalia do corpo caloso. Macrocrania ocorre em $20 \%$ dos casos de disgenesia do corpo caloso, estando relacionada a cistos inter-hemisféricos ${ }^{(\mathbf{1 , 2})}$.

Lipomas são raros defeitos da linha mediana, podendo apresentar componentes intracerebral, extra-axial e extracraniano. Dos lipomas intracranianos, o mais comum é o do corpo caloso, representando aproximadamente $30 \%$ do total. Outras localizações dos lipomas intracranianos são as regiões da placa quadrigeminal, cis-

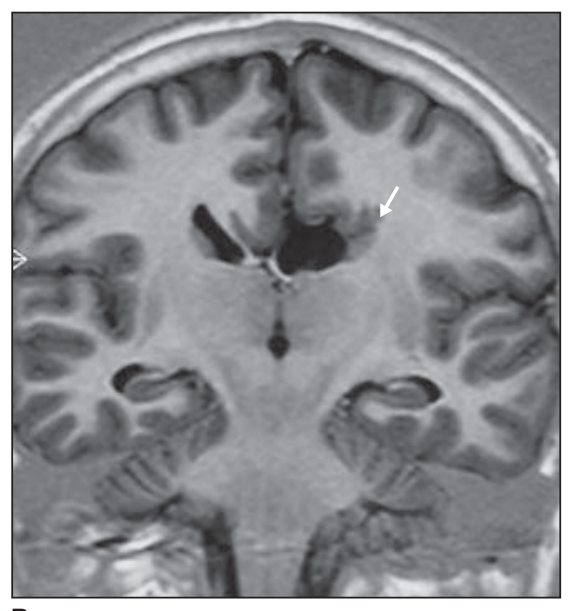

B terna ambiente e na tela coróide do ventrículo lateral. Segundo a literatura, as mulheres são mais freqüentemente afetadas, porém, há relatos de discreto predomínio desta afecção no sexo masculino. O lipoma de corpo caloso associa-se a diferentes graus de agenesia de corpo caloso. Tem sido proposto que quanto mais cedo for o surgimento do lipoma, mais grave será a anomalia resultante do corpo caloso. Desde que o corpo caloso se origina de anterior para posterior, os lipomas com o aparecimento precoce devem ser mais anteriormente situados ${ }^{(\mathbf{9 , 1 0})}$.

\section{Achados de imagem}

Os achados de imagem variam de acordo com o grau de acometimento do corpo caloso. Na agenesia total ou parcial do corpo caloso, os ventrículos laterais estão separados e não-convergentes. Nos cortes axiais de TC e RM os ventrículos laterais são paralelos, apresentando cornos frontais pequenos e com as bordas mediais côncavas, associados a um aumento desproporcional dos cornos occipitais (colpocefalia). A colpocefalia está associada, em $40 \%$ dos casos, a disgenesia do corpo caloso ${ }^{(2,4,7)}$ (Figura 4).

Nas imagens sagitais, a RM mostra ausência parcial ou total do corpo caloso, não identificação do giro do cíngulo, e os sulcos e giros corticais da face medial dos

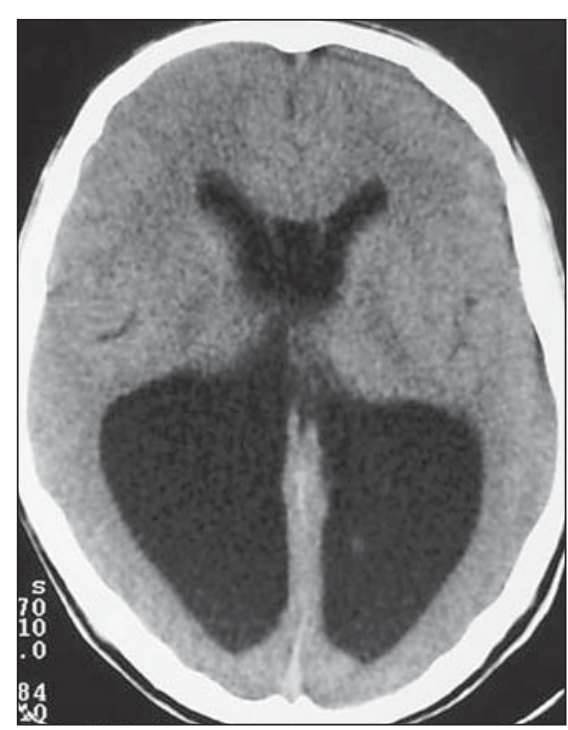

Figura 4. Agenesia parcial do corpo caloso (caso10). TC axial sem contraste endovenoso - aumento desproporcional dos cornos occipitais dos ventrículos laterais (colpocefalia) e paralelismo ventricular. 
hemisférios irradiam a partir do terceiro ventrículo (estenogiria). Se a agenesia for parcial, identificam-se o corpo e o joelho do corpo caloso ${ }^{(2,7)}$ (Figura 1A).

Um aspecto muito importante a ser observado na agenesia e na hipogenesia do corpo caloso são as bandas de Probst, que são fibras calosas não decussadas, as quais passam paralelamente à fissura inter-hemisférica na parede medial do ventrículo lateral. Estas bandas são mais espessas anteriormente e reduzem-se no sentido posterior. Isto explica o menor diâmetro dos cornos frontais em relação aos ventrículos laterais. Estas bandas são peculiares a estas condições e aparentemente não apresentam terminações nervosas significativas $^{(2,4,6,7)}$.

O terceiro ventrículo é grande e em situação mais cranial, podendo situar-se entre os ventrículos laterais. Há, também, uma comunicação do terceiro ventrículo com a fissura inter-hemisférica. Pode ser observado cisto inter-hemisférico, que em geral é grande e separa os dois hemisférios, podendo apresentar-se multiloculado (Figura 5). Deve-se fazer diagnóstico diferencial destes cistos associados a agenesia do corpo caloso, daqueles de linha mediana, tais como os porencefálicos e cistos dorsais associados a holoprosencefalia ${ }^{(2,7)}$.

A disgenesia do corpo caloso pode associar-se a ausência de outros tratos comissurais, como a comissura anterior e hipocampal $^{(7)}$.

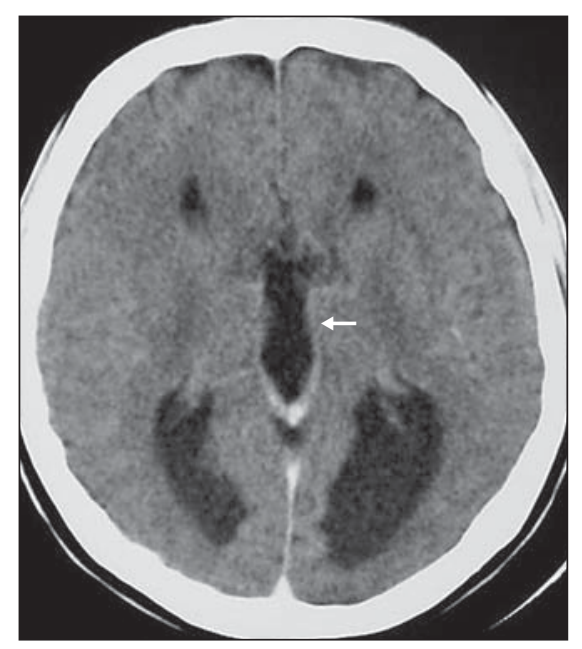

A

Figura 5. Agenesia total do corpo caloso (caso 12). TC axial sem contraste endovenoso. A: Colpocefalia e terceiros ventrículos elevados, situados entre os ventrículos laterais (seta). B: Paralelismo dos ventrículos laterais (setas).

O lipoma do corpo caloso foi descrito pela primeira vez, em autópsia, por Reil, em 1812. Outrora, o diagnóstico por imagem era feito pela radiografia simples do crânio e pela pneumoencefalografia. Com o advento da TC e da RM, este diagnóstico tornou-se mais fácil e preciso. As imagens de RM ponderadas em T1 são altamente específicas para diagnosticar e mostrar as relações anatômicas do lipoma. Em 40\% dos pacientes com lipoma observamos agenesia calosa ${ }^{(\mathbf{9 , 1 1})}$.

Com base na morfologia e localização em relação ao corpo caloso, os lipomas podem ser de dois tipos: túbulo-nodular e curvilíneo. Esta diferença ocorre devido ao tempo de desenvolvimento dos lipomas relacionados à formação do corpo caloso e estruturas encefálicas adjacentes. Acredita-se estarem os lipomas túbulo-nodulares presentes na formação do joelho do corpo caloso e o curvilíneo se originando mais tarde no desenvolvimento ${ }^{(\mathbf{1 0})}$.

O lipoma túbulo-nodular é visto como lesão volumosa, arredondada ou levemente maior no sentido longitudinal, localizado mais anteriormente, sendo duas vezes mais freqüente e associado em maior grau a anormalidades e sintomas, tais como convulsões, displasias faciais ou síndrome frontal. O epicentro dos lipomas túbulonodulares tende a ocorrer no joelho do corpo caloso $(83 \%)$, estendendo-se rostralmente dentro da fissura inter-hemisférica. Estes lipomas são circundados por

B

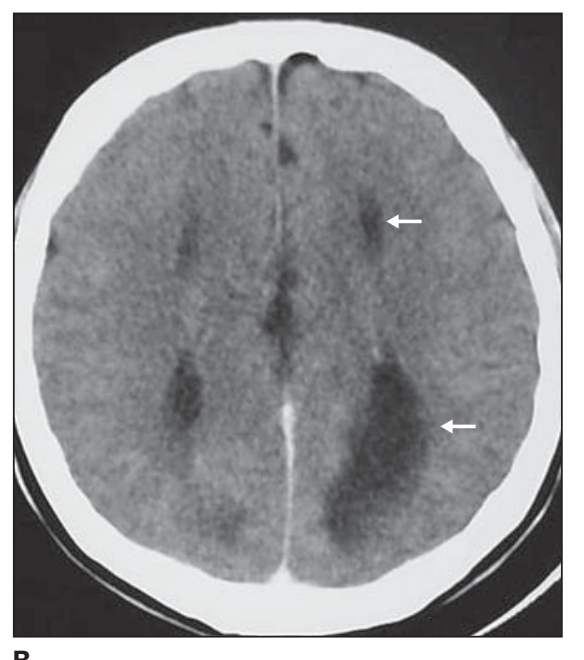

\section{Associações}

A maioria das estruturas telencefálicas é formada entre a $10^{\underline{a}}$ e a $12^{\underline{a}}$ semanas de gestação; assim, anomalias do corpo caloso freqüentemente estão associadas a alterações de outras estruturas ${ }^{(\mathbf{6})}$.

A migração neuronal está diretamente envolvida na formação do precursor do corpo caloso, assim há uma relação causal entre a formação do corpo caloso e déficit de migração neuronal ${ }^{(3)}$.

Aproximadamente 12\% das disgenesias do corpo caloso estão associadas a hipoplasia ou ausência da foice cerebral ${ }^{(\mathbf{1})}$.

Existem várias anomalias associadas a disgenesia do corpo caloso e ocorrem em quase metade dos casos, dentre elas podem-se citar as mais comuns: má-formação 


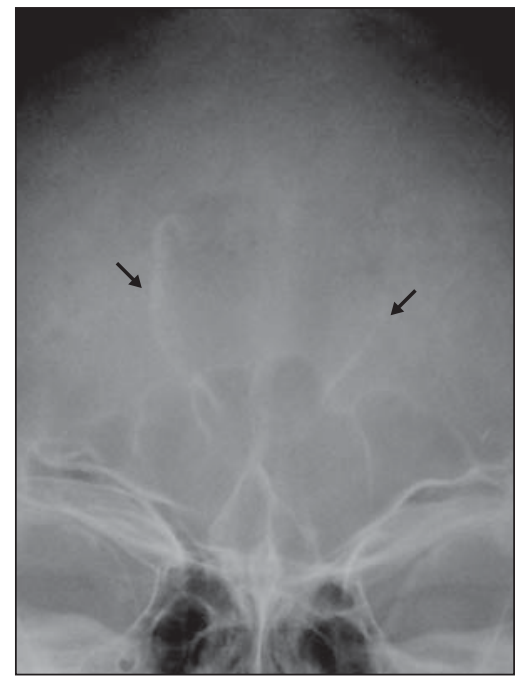

A

Figura 6. Agenesia total do corpo caloso (caso 6). Radiografia simples do crânio. A: Calcificações lineares em forma de vírgula projetadas na região frontal paramediana bilateral. B: Imagem radiotransparente na projeção em perfil. C: TC axial sem contraste endovenoso - lesão expansiva com densidade de gordura localizada na linha média em topografia do corpo caloso (seta), com calcificações periféricas (contorno de seta), associada a agenesia completa do corpo caloso.

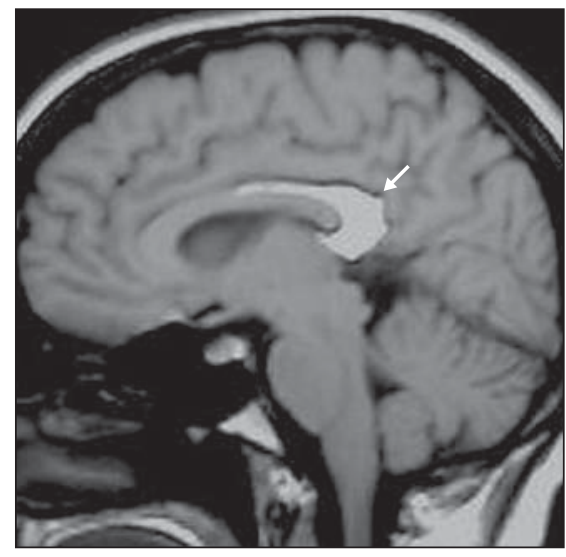

Figura 7. Agenesia parcial do corpo caloso (caso 11). RM SE T1 sagital - imagem de hipersinal em forma de vírgula pericalosa associada a ausência do esplênio do corpo caloso (seta).

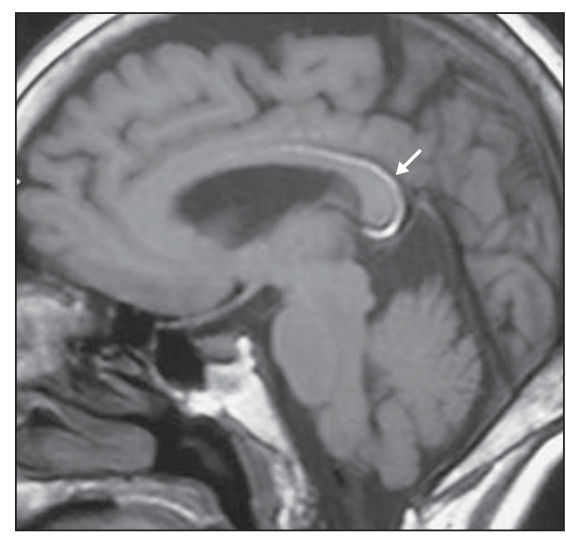

Figura 8. Corpo caloso normal (caso 3). RM SE T1 sagital - imagem de hipersinal em forma de vírgula pericalosa (seta).

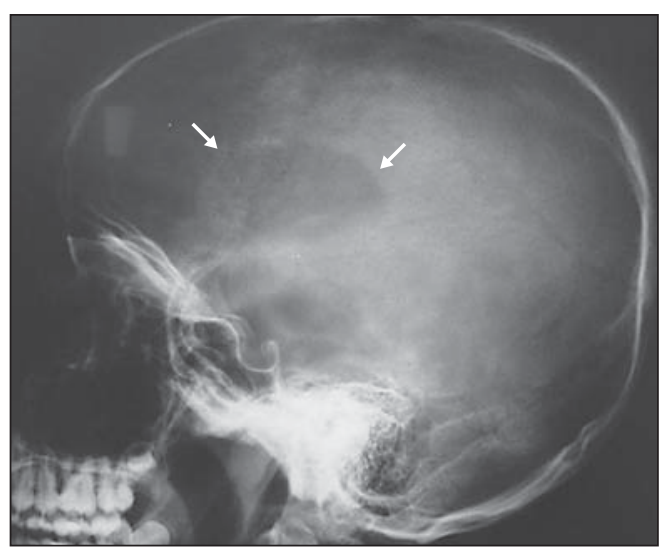

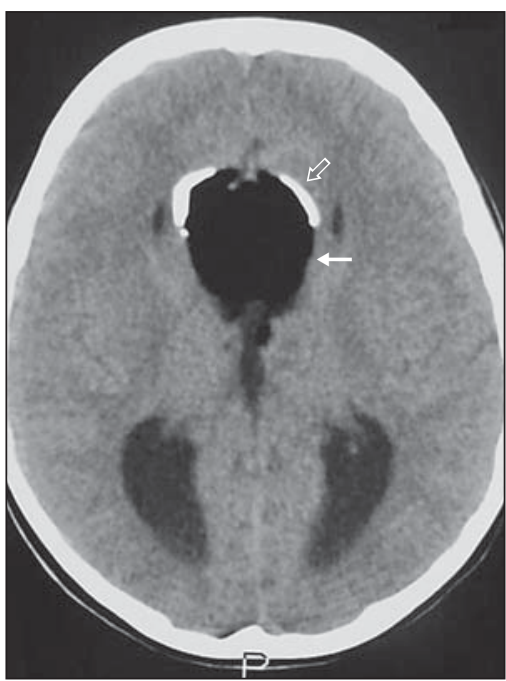

do tipo Chiari II (Figura 9), complexo de Dandy-Walker (Figura 10), distúrbios de migração neuronal (agiria, paquigiria, polimicrogiria, heterotopias e esquizencefalia) (Figura 11), distúrbios da linha média (encefaloceles, anomalias faciais), além de outras mais raras como anomalias oculares, alguns tipos de trissomias, síndrome de

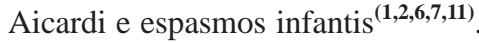

Os lipomas túbulo-nodulares são mais comumente associados a agenesia calosa

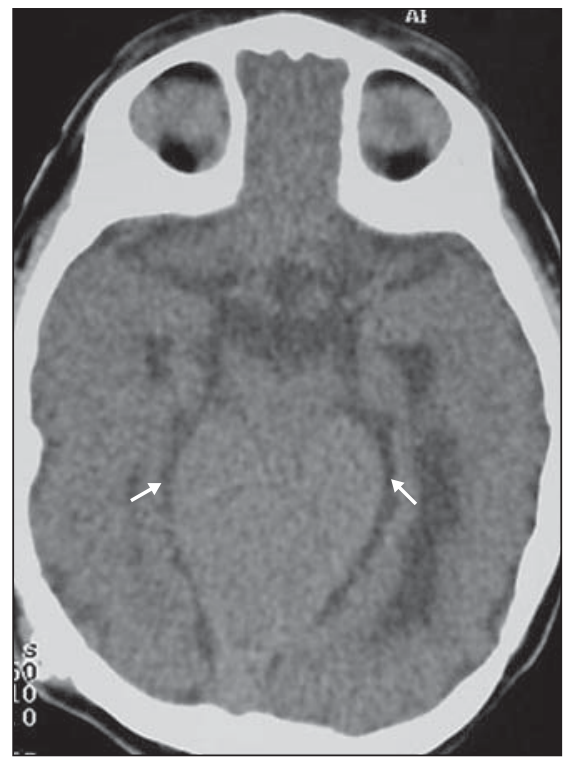

A

Figura 9. Agenesia parcial do corpo caloso associada a Chiari tipo II (caso 1). TC axial sem contraste endovenoso. A: Mesencéfalo circundado por cerebelo, caracterizando o "sinal da banana" (setas). B: Colpocefalia com paralelismo dos ventrículos laterais. do que os curvilíneos. As anomalias relacionadas aos lipomas podem ser similares nos dois tipos, porém com diferentes níveis de gravidade, como, por exemplo, o lipoma do plexo coróide e calcificações periféricas, as quais são encontradas nas duas variedades de lipoma. Algumas anormalidades, como displasia facial, defeito ósseo frontal, encefaloceles e lipomas frontais, somente são encontradas nos lipomas túbulo-nodulares ${ }^{(\mathbf{1 0})}$.

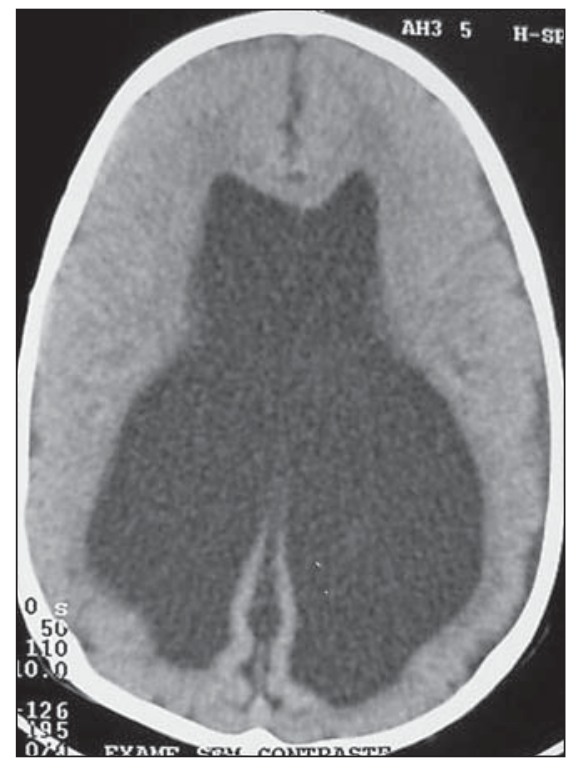

B 


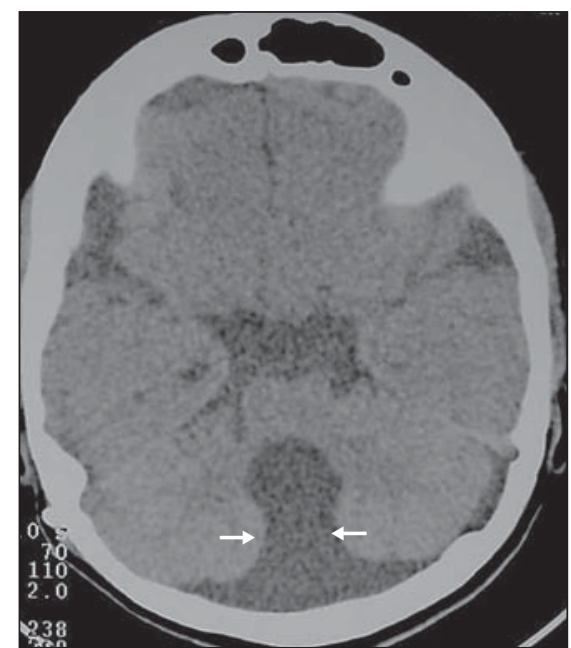

A

Figura 10. Agenesia total do corpo caloso associada a cisto de Dandy Walker (caso 7). TC axial sem contraste endovenoso. A: Agenesia do vérmis cerebelar (setas) e cisto de fossa posterior. B: Deformidade dos ventrículos laterais e ausência do joelho e esplênio do corpo caloso (setas).

\section{CONCLUSÃO}

O surgimento de métodos de diagnóstico por imagem não-invasivos, como a TC e a RM, permitiu uma maior facilidade no diagnóstico das disgenesias do corpo caloso e enfermidades correlatas. Este artigo mostra, de forma simplificada, estes distúrbios, auxiliando, dessa maneira, na interpretação diagnóstica.

\section{REFERÊNCIAS}

1. Kendall BE. Dysgenesis of the corpus callosum. Neuroradiology 1983;25:239-56.

2. Gary AP. Developmental disorders. In: Edelman

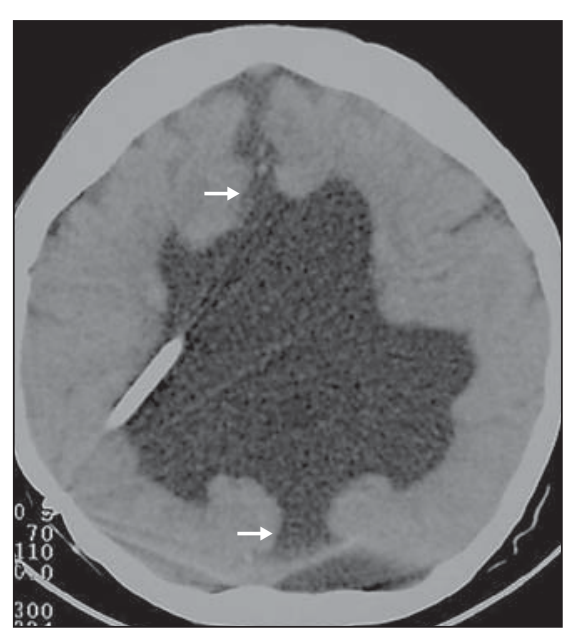

B

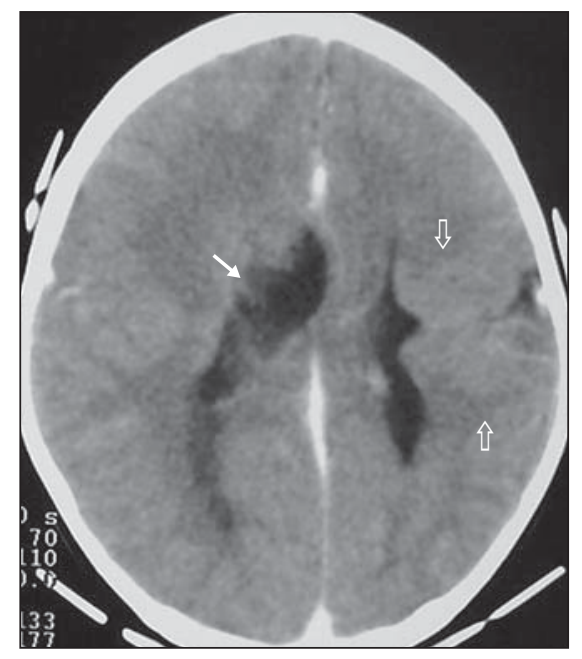

Figura 11. Agenesia parcial do corpo caloso associada a esquizencefalia (caso 2). TC axial sem contraste endovenoso - paralelismo dos ventrículos laterais com cisto inter-hemisférico (seta) e fenda circundada por substância cinzenta estendendo-se da borda ventricular à superfície cortical localizada no lobo frontal esquerdo (contornos de setas).

7. Osborn AG. Disorders of neural tube closure. In: Osborn AG, ed. Diagnostic neuroradiology. 2nd ed. St. Louis, MO: Mobsy, 1994:29-35.

8. Fisher RM, Cremin BJ. Lipoma of the corpus callosum: diagnosis by ultrasound and magnetic resonance. Pediatr Radiol 1988;18:409-10.

9. Suzuki M, Takashima T, Kadoya M, et al. Pericallosal lipomas: MR features. J Comput Assist Tomogr 1991;15:207-9.

10. Tart RP, Quisling RG. Curvilinear and tubulonodular varieties of lipoma of the corpus callosum: an MR and CT study. J Comput Assist Tomogr 1991;15:805-10.

11. Diebler C, Dulac O. Malformations du cerveau et du crâne. In: Diebler C, Dulac O. Neurologie et neuroradiologie infantiles. Maladies du cerveau et du crâne. 2nd ed. Paris: Springer-Verlag, 1990:116. 